\title{
APRECIACIONES RELATIVAS A LAS MANIFESTACIONES DE LA RESPONSABILIDAD SOCIAL EMPRESARIAL COMO DECLARACIÓN UNILATERAL DE VOLUNTAD
}

\author{
APPRECIATIONS CONCERNING THE MANIFESTATIONS OF CORPORATE \\ SOCIAL RESPONSIBILITY AS UNILATERAL DECLARATION OF WILL
}

David López Jiménez ${ }^{1}$

\section{RESUMEN}

Es conocido por todos que, en la actualidad, un gran número de empresas efectúan, de manera particular, actuaciones que pueden englobarse en lo que se denomina Responsabilidad Social Empresarial. Aunque las calificaciones de los documentos, en los que la misma se materializa, son relativamente numerosas, cuando son implantadas y puestas en práctica por la propia empresa sin existir un organismo externo, imparcial $e$ independiente, que verifique su observancia- ostentan la nota común de constituir, desde el plano jurídico, una declaración unilateral de voluntad.

\section{Palabras clave}

Consumidores, declaración unilateral de voluntad, negocios, responsabilidad social empresarial, verificación

\section{ABSTRACT}

It is very well known that, nowadays, a large number of companies participate, in a particular way, in actions that can be included in what is called Corporate Social Responsibility. Although the scores of the documents in which it is included are relatively numerous, when it is implanted and implemented by the own company -without the existence of an external organism which is impartial and independent for its verification- have the common mark of the establishment, from a legal point of view, of a unilateral declaration of will.

\section{Keywords}

Consumers, unilateral declaration of will, business, corporate social responsibility, verification

\section{INTRODUCCIÓN}

La empresa durante un amplio lapso de tiempo ha sido considerada como una entidad cuya finalidad esencial se fundamentaba, en gran medida, en maximizar el valor de los accionistas. Aunque, en la actualidad, no se desconoce la relevancia que ostenta la obtención del rendimiento del accionista, se tienen en consideración otros parámetros complementarios de interés. Así, entre otros, se estima de notable interés el hecho de que la empresa actúe de manera responsable en el contexto en el que cotidianamente opera. Todo ello entronca con lo que puede considerarse la gestión empresarial. De esta manera, vinculado con cuanto comentamos, se ponen en marcha un elenco relativamente

Licenciado, con dos doctorados. Ha realizado diferentes postgrados universitarios en varias Universidades españolas Es autor de varias monografías, así como de más de 200 publicaciones indexadas. Forma parte de 16 comités científicos y consejos editoriales, además de revisor de revistas. Miembro de numerosos proyectos de investigación, ha participado en congresos nacionales y ha efectuado estancias de investigación en distintos países europeos. Es profesor investigador. 
amplio de técnicas de Responsabilidad Social Empresarial -RSE-.

Con todo, en base a tales actuaciones, que se engloban dentro de esta última figura, se tienen en cuenta los intereses de la comunidad en la que la empresa correspondiente opere.

La RSE engloba múltiples ámbitos materiales $y$, precisamente, por tal carácter, es difícil abarcarla en sus diversas manifestaciones. Tal aspecto, a su vez, forma parte de la ética y de la imagen que las mismas proyectan hacia el exterior, que se relaciona con la denominada reputación empresarial. De esta manera, es una suerte de aspiración de las empresas que, en cierta medida, condicionan su estrategia futura. Estamos, en suma, ante una herramienta estratégica de posicionamiento y valoración en el mercado.

Lo que, de alguna manera, está planteándose es un cambio notable de perspectiva respecto a la contribución que se espera de la empresa en relación a la sociedad. Nótese que no estamos hablando únicamente de prácticas empresariales, en cuanto a determinados bienes $y / o$ servicios, sino que aludimos a ciertos valores.

Si bien la RSE es un tema crucial, a fecha $\mathrm{de}$ hoy, sobre el que se han escrito ríos de tinta, sobre todo desde el plano empresarial, no puede afirmarse lo mismo desde el plano jurídico, cuando las implicaciones de tal figura son, igualmente, relevantes. En este sentido, en el presente artículo, efectuaremos ciertas apreciaciones, de carácter general, sobre esos puntos. Seguidamente, nos ocuparemos del concepto y caracteres de las manifestaciones más paradigmáticas de esta sugerente herramienta, entre las que ocupan un lugar de preeminencia-en gran medida por su frecuente recurso en la práctica- de los denominados códigos de conducta. Estos únicamente, como veremos, pueden haber sido elaborados, puestos en práctica y controlados por parte de la propia empresa que los adopta. En el caso que comentamos, no existirá un organismo de control que verifique la observancia de los compromisos asumidos, en los diversos ámbitos, inicialmente. Por ello, la naturaleza jurídica de tales figuras, con lo que, a su vez, ello comporta, es una declaración unilateral de voluntad.

\section{NOTAS EN TORNO AL ESTADO ACTUAL DE LA RESPONSABILIDAD SOCIAL EMPRESARIAL}

La concepción de que la empresa constituye una organización que desempeña una función de primer orden en la sociedad, no limitada, con carácter exclusivo, a la generación de riqueza y de empleo es progresivamente más aceptada.

En efecto, entendemos que la reducción de la empresa a una ficción legal, detrás de la cual solo existe una serie de contratos privados, se olvida de que existe una empresa como organización, coalición o asociación de agentes económicos aparte de los individuos que la componen.

Las empresas, en la actualidad, coexisten en un contexto altamente competitivo que les obliga a realizar una diferenciación, en todos los sentidos, para poder subsistir en los mercados internacionales. Las empresas necesitan encontrar nuevas fuentes de ventaja profesional que les permitan ser competitivas en el tiempo. Es aquí donde radica la importancia de la RSE en el mundo de los negocios que hoy día conocemos.

El término RSE no tiene, a tenor de las consideraciones doctrinales actualmente existentes, un significado unánime, si bien consideramos que representa una expresión cercana a la comunicación de los valores. Aun así, debe valorarse que la responsabilidad social corporativa en la actualidad continúa siendo un término todavía difuso que se traduce en actuaciones y objetivos diferentes en función de la empresa, entidad u organización que la integra.

Implica una mayor implicación de la empresa en los retos y problemas de la sociedad actual. Sin perder de vista las consideraciones expuestas, la RSC puede definirse como el conjunto de obligaciones y compromisos -de carácter legal y ético- nacionales e internacionales, 
con los grupos de interés, que se derivan de los impactos que la actividad y operaciones de las organizaciones producen en múltiples y diversos ámbitos.

De igual modo, ha de advertirse que la RSE exige a la empresa, ante todo, una convicción ética integral en su raíz y una forma de concebir las relaciones que se mantienen en la sociedad en las que se actúa basadas en la reciprocidad y actitud de servicio para dar respuesta a sus demandas. La forma más frecuente de integración de la ética en la nueva gestión de la empresa está siendo su incorporación y formalización en diversos documentos escritos que algunos autores incluyen bajo el término de Declaraciones Éticas Corporativas.

Existe una nutrida corriente doctrinal que entiende que las actuaciones susceptibles de ser englobadas en la RSE son, en esencia, una pura estrategia de marketing. Según tal opinión, las acciones aptas de ser integradas en aquella, persiguen, a través de un fortalecimiento de la imagen de la compañía, la búsqueda de un suculento incremento de los beneficios, visible en los documentos corporativos aprobados al respecto. Uno de los signos visibles de la existencia de un compromiso corporativo con el comportamiento ético es, precisamente, un código de conducta escrito. Bajo la locución códigos de conducta, se albergan determinadas reglas de comportamiento correcto establecidas por el gremio de los propios interesados, en ese concreto sector de actividad, con la finalidad de ordenar sus relaciones recíprocas, entre sí, y, además, con el resto de los agentes económicos.

La práctica totalidad de asociaciones profesionales, sectores de actividad, grupos de empresas, organización, institución o colectivo se ha planteado, de una $\mathrm{u}$ otra forma, la elaboración de pautas de conducta comunes, ha elaborado proyectos de códigos $e$, incluso, posee un código de conducta con, más o menos, tradición. Ahora bien, en muchas ocasiones, nos encontramos ante códigos de conducta voluntarios, instaurados y verificados, por la propia empresa. Podría parecer, en esta línea, que lo que se busca, en gran parte, más que la asunción de verdaderos compromisos, es, lo que podría denominarse una labor de marketing empresarial.

El criterio enunciado, a nuestro juicio, puede encontrar cierto respaldo en el hecho de que, en el supuesto enunciado, no existe un organismo, independiente e imparcial, que evalúe el grado de cumplimiento de los códigos de conducta. En efecto, son muy escasas las empresas que recurren a auditorías para valorar la observancia que las mismas efectúan de los códigos de conducta que voluntariamente han puesto en práctica.

Seguidamente, al concepto y caracteres de esta sugerente figura, desde un plano legal, para, posteriormente, aludir a la posible naturaleza jurídica de la misma.

\section{CONSIDERACIONES LEGALES RELATIVAS A LOS DENOMINADOS DOCUMENTOS DE BUENAS PRÁCTICAS}

Aunque resultan numerosos los documentos supraestatales, europeos, nacionales $y$ autonómicos que aluden a la autorregulación en general y los códigos de conducta en particular, lo cierto es que son muy limitados los preceptos que delimitan su significado. Dispone, en este sentido, el art. 2.f) de la Directiva 2005/29/CE del Parlamento Europeo y del Consejo, de 11 de mayo de 2005, relativa a las prácticas comerciales desleales de las empresas en sus relaciones con los consumidores en el mercado interior (Directiva de prácticas comerciales desleales) que es un "acuerdo o conjunto de normas no impuestas por disposiciones legales, reglamentarias o administrativas de un Estado miembro, en el que se define el comportamiento de aquellos comerciantes que se comprometen a cumplir el código en relación con una o más prácticas comerciales o sectores económicos concretos" 2 .

\footnotetext{
Repárese en que la Ley española que transpone la mencionada Directiva -Ley 3/1991, de 10 de enero, de Competencia Desleal (LCD), después de la reforma de 2009- no recoge, en su articulado, la definición enunciada. Ahora bien, dada la supremacía que ostenta el Derecho comunitario, debe regir en toda su extensión. En cualquier caso, debe advertirse que hasta la LCD no existía en nuestro país una norma que reconociese y regulase, con carácter general y de manera sistemática,
} 
Por el contrario, son abundantes y muy diversas, entre sí, las definiciones doctrinales que se han formulado en relación a los códigos de conducta. En todo caso, dependen, en gran parte, del escenario en el que los mismos operan ${ }^{3}$. Dicho esto, antes de dar una posible definición, podemos enunciar, con independencia del ámbito para el que hayan sido diseñados, la concurrencia de dos objetivos. En primer término, con su aprobaciónsi es que se redacta unilateralmente por la empresa (a estos serán a los que preferentemente nos referiremos)- o asunción -en el supuesto de que haya sido aprobado por otra entidad y la única vía para manifestar el compromiso sea en virtud de la adhesión-, se persigue dotar de un plus de calidad al bien o servicio de la empresa que lo asume $^{4}$-que es, a su vez, una nota diferencial con respecto a la competencia-. Tal medida, mejorará la reputación o la buena imagen de la empresa que se obliga a cumplir el tenor del código de buenas prácticas 5 . En segundo lugar, derivado del mencionado, se busca desplegar una imagen de confianza y legitimidad en su actuación.
Una de las notas de los códigos de conducta, que precisamente puede inferirse de la definición operada por la Directiva de prácticas comerciales desleales, es su caráctervoluntario ${ }^{6}$. En efecto, como regla general, su vinculación obedece a la libertad que el empresario tiene para acordar, en su comportamiento cotidiano, su plena observancia?

Tales herramientas -los códigos de conducta-, como su propia denominación ${ }^{8}$ pone de relieve, pretenden instaurar normas de comportamiento. El contenido de gran parte de tales documentos pretende ser una determinada forma de conexión entre la ética y el Derecho.

Los códigos de conducta pueden incluir no solo una relación de valores, sino también una descripción relativamente amplia de las conductas que se consideran acordes con tales valores, pero, además, con carácter complementario, de las conductas reprobables

la figura de los códigos de conducta. Asimismo, debe considerarse que es una de las novedades más significativas de la nueva disciplina. En este último sentido, Tato Plaza, A. (2010) "Líneas generales de la reforma de la reforma del Derecho español contra la competencia desleal (parte II)", Autocontrol, núm. 150, p. 12.

3 Aunque operan exitosamente en numerosos escenarios, en algunas ocasiones, se efectúa un uso poco riguroso del término "códigos de conducta". De hecho, existen resoluciones judiciales en las que se evidencia un uso atípico (y, en cierta medida, impropio) del mencionado término. En otras palabras, con tal expresión, no se aludía, en modo alguno, a un conjunto de normas derivadas de la autonomía de la voluntad de las partes. Así, a título de ejemplo, cabe referirse a la SAP de Tenerife de 7 de febrero de 2003 (JUR 2003/141153) y SAP de Córdoba de 23 de mayo de 2003 (JUR 2003/152479).

Igualmente, Maluquer De Motes Bernet, C. (2011) "Códigos de conducta y buenas prácticas en la gestión da datos personales". En Llacer Matacás, M.R. (Coord.), Protección de datos personales en la sociedad de la información u la vigilancia, La Ley, Madrid, p. 125; Candela Quintanilla, R.M. (2012) "II Encuentro Nacional de Agentes Oficiales Prescriptores de Confianza Online", Autocontrol, núm. 172, p. 15.

5 Así, López Jiménez, D. y Martínez López, F.J. (2010) "Nuevas tendencias en materia de responsabilidad social corporativa: los códigos de conducta reguladores del comercio electrónico", Revista de Responsabilidad Social de la Empresa, núm. 1, pp. 41-72.

6 Arnaud, A.J. (2003) Critique de la raison juridique. Gouvernants sans frontirres - Entre mondialisation et post-mondialisation, Vol. 2, LGDJ, París; Martí Miravalls, J. (2008) "Los códigos de conducta en las redes de franquicia: el modelo Americano versos el europeo", Revista de Derecho Mercantil, núm. 269, p. 953; Cayón de las Cuevas, J. (2011) "Regulación y autorregulación en el comercio electrónico: especial consideración de los códigos de conducta como instrumento de soft law". En Tomilla Urbina, J. (Dir.) y Álvarez Rubio, J. (Coord.), La protección jurídica de los consumidores como motor de desarrollo económico, Thomson Reuters y Civitas, Navarra, p. 561.

Determina, en este sentido, el Libro Verde, de 18 de julio de 2001, de la Comisión de las Comunidades Europeas, en relación a fomentar un marco europeo para la responsabilidad social de las empresas, que código de conducta es la "declaración formal de los valores y prácticas comerciales de una empresa y, algunas veces, de sus proveedores. Un código enuncia normas mínimas y el compromiso de la empresa de cumplirlas y de exigir su cumplimiento a sus contratistas, subcontratistas, proveedores y concesionarios. Puede ser un documento complejo que requiera el cumplimiento de normas precisas y prevea un mecanismo coercitivo complicado".

8 Ahora bien, ciertos autores, como De la Cueste Rute, J.M. (2008) "La autorregulación como regulación jurídica". En Real Pérez, A. (Coord.), Códigos de conducta y actividad económica: una perspectiva jurídica, Marcial Pons, Madrid-Barcelona, p. 33, Universidad Complutense de Madrid, se posicionan a favor de la expresión "códigos de buenas prácticas". A su entender, resulta adecuada, dado que los mismos expresan estándares de conducta con un cierto reconocimiento social capaces de medir su diligencia o su carencia en el obrar susceptible de desencadenar la responsabilidad del sujeto. En todo caso, como dispone Duprat, J.P. (2010) "Los códigos de conducta vistos por un jurista francés". En Real Pérez, A. (Coord.), Códigos de conducta y actividad económica: una perspectiva jurídica, Marcial Pons, Madrid-Barcelona, p. 56, la denominación que se atribuya a la figura que comentamos, no determinará, por sí sola, la calificación jurídica. 
por ser contrarias a los mismos, que, según el caso, serán objeto de sanción.

Las normas de conducta o comportamiento que los integran, en la inmensa mayoría de los casos, son de producción no estatal ni pueden considerarse usos sociales que puedan ser estimados como costumbre. Sobre este último particular, debería señalarse que, dado que, a tenor del art. 281.2 de la LEC, la costumbre debe probarse, podrían suscitarse ciertos problemas si se quisiera alcanzar su eficacia en el supuesto de que no existiera una clara voluntad de observancia de la entidad que asume el código de conducta.

Naturalmente, resulta necesario que los mismos sean públicos ${ }^{9}$, en el sentido de que la vigencia de los códigos de conducta puedan ser conocidos por sus destinatarios. En realidad, de nada serviría, para los fines para los que los mismos han sido concebidos su ocultación ${ }^{10}$.

\section{ESTIMACIÓN COMO DECLARACIONES UNILATERALES DE VOLUNTAD}

Una vez que hemos analizado, de manera somera, los conceptos de RSE, así como una de sus manifestaciones más paradigmáticas y cuáles son los códigos de conducta, seguidamente aludiremos a su posible naturaleza jurídica. La misma resulta aplicable a aquellas figuras que han sido unilateralmente puestas en práctica $y$, a su vez, verificadas por la propia empresa que las implanta.
Elsupuesto al que nos referimos debe distinguirse de aquellos otros casos en los que el documento de buenas prácticas haya sido asumido, de manera voluntaria, por una determinada empresa, estando su verificación a cargo de un tercero encargado de su observancia. En esta situación, a la que, insistimos, no nos referiremos, en el presente estudio, lo que impera es lo que podría denominarse como sistema de autodisciplina. Para su existencia, deberán necesariamente concurrir dos presupuestos. Se trata, por un lado, del documento de referencia ${ }^{11}$ -que podrá ser un código de conducta- y, por otro, del organismo de control, imparcial $e$ independiente, que se encargará de velar por su plena observancia ${ }^{12}$.

Hecha tal apreciación, debemos señalar que si los documentos de buenas prácticas han sido instaurados y verificados por la propia empresa -sin, a sensu contrario, existir un organismo externo responsable de su observanciapueden estimarse declaraciones unilaterales de voluntad ${ }^{13}$. La promesa unilateral no tiene eficacia obligatoria, si es inter vivos, busca incesantemente la aceptación del beneficiario, si es mortis causa, exige la forma de esta clase de actos jurídicos unilaterales, so pena de nulidad en caso de inobservancia. La no admisibilidad se limita a las promesas atípicas, no a las típicas, y aquí cabe incluir tanto las legalmente típicas -títulos valores y actos unilaterales mortis causa- cuanto las socialmente típicas -promesa pública-.

Ahora bien, la jurisprudencia del TS, desde antaño -STS de 30 de septiembre de 1975-,

No nos referimos a que se publiquen en boletines oficiales o públicos que, además, tampoco sería posible.

10 El art. 14.1 de la Directiva 2008/122, de 14 de enero, relativa a la protección de los consumidores en los contratos de aprovechamiento por turnos de bienes de uso turístico, adquisición de productos vacacionales de larga duración, de reventa e intercambio, dispone que "los Estados miembros tomarán las medidas apropiadas para informar a los consumidores de las disposiciones de Derecho interno por las que se transpone la presente Directiva e instarán, en su caso, a los comerciantes y a los responsables de los códigos a que informen a los consumidores de sus códigos de conducta". De igual forma, como determina el Considerando 22 de la citada norma europea, con objeto de obtener un nivel elevado de protección de los consumidores, se podría informar a las organizaciones de consumidores de la elaboración de códigos de conducta y asociarlas a su redacción.

11 La denominación de las figuras derivadas de la autorregulación es radicalmente diversa a las que ostentan las fuentes jurídicas clásicas.

12 La nueva Ley de Competencia Desleal únicamente reconoce aquellos sistemas de autodisciplina que incluyan mecanismos de resolución extrajudicial de litigios que se fundamenten y hayan sido objeto de reconocimiento a tenor de lo previsto en la Resolución del Consejo de 25 de mayo de 2000 y que, como tales, hayan sido notificados a la Comisión Europea.

13 Así, Illescas Ortiz, R. (2003) "La autorregulación, entre la quiebra de la relatividad y la obligatoriedad de la declaración unilateral de voluntad", Derecho Privado y Constitución, núm. 17, pp. 305 y 306; Rodríguez de las Heras Ballel, T. (2009) "Espacio digital y autorregulación". En Real Pérez, A. (Coord.), Códigos de conducta y actividad económica: una perspectiva jurídica, Marcial Pons, Madrid-Barcelona, p. 163. 
exige, como requisito para la eficacia de la declaración unilateral de voluntad, además de su aceptación, la existencia de una relación jurídica preexistente, es decir, de una causa de la obligación asumida por el declarante.

No obstante, debemos ser conscientes de que en el Derecho patrimonial español tanto la gran tradición doctrinal y el actual pensamiento civilista $^{14}$ dominante ${ }^{15}$ como la jurisprudencia ${ }^{16}$ excluyen a dicha voluntad unilateral de la teoría de las fuentes de las obligaciones ${ }^{17}$. Sin embargo, algunas sentencias admiten la virtualidad creadora de obligaciones a la declaración unilateral de voluntad, aunque de manera plenamente excepcional y restrictiva, vinculando la cuestión con el tema de la causa específica de la obligación contraída ${ }^{18}$.

Se observa, de esta manera, cierta coherencia con lo establecido en el Código Civil. De igual modo, son muy limitados los códigos civiles que, en el Derecho comparado, reconocen la eficacia de la declaración unilateral de voluntad en supuestos excepcionales. Así, acontece en el código alemán (art. 305), en los códigos suizo, de Polonia, de Italia (art. 1987), y en los códigos latinoamericanos más modernos: por cierto, Brasil, de 1916, le dedica un título especial (arts. 1505 y siguientes); el de Perú de 1936 (arts. 1802 y siguientes) y el de México (arts. 1860 y siguientes). Ahora bien, el art. 2107 de los Principios del Derecho Europeo de Contratos dispone que "una promesa realizada con la voluntad de quedar legalmente vinculado sin aceptación es vinculante". En los comentarios unidos a tales Principios, sin embargo, se establece que únicamente algunos ordenamientos europeos respaldan esa posición -citando, entre los mismos, el finlandés y el danés-. En todo caso, la mayor parte del Derecho continental europeo exige la aceptación.

Tal posicionamiento, sin embargo, solo es posible en el caso de que el código de conducta fuera impuesto o aprobado, por parte del empresario, como declaración de buenas prácticas formulado por sí mismo -sin existir una entidad promotora detrás, ni un órgano de control encargado de su aplicación-, pero, asimismo, frente a sí Respecto a tal postura, cabría matizar que, en cualquier momento, quien realizó la promesa -promitente-, en el ámbito de la declaración unilateral de voluntad, podría revocarla. De este modo, imperaría cierta inseguridad jurídica. Asimismo, podría considerarse que la promesa unilateral solo puede engendrar una situación de vinculación del promitente, mientras no sea revocada, que ostenta un mero valor preparatorio de la constitución de la relación por virtud de la aceptación del destinatario.

Cuando la promesa unilateral hubiera sido aceptada por su destinatario, es decir el receptor de la oferta la haya aceptado, ya no sería la voluntad unilateral, sino el concurso de voluntades el que determinaría el nacimiento de la obligación ${ }^{19}$. Ello acontecería en el caso de

14 Díez-Picazo, L. (1996) Fundamentos del Derecho Civil Patrimonial. Las relaciones obligatorias, Tomo 2, Civitas, Madrid, p. 144, determina, a tal efecto, que el fenómeno químicamente puro de la declaración unilateral de voluntad no es suficiente para constituir una genuina declaración obligatoria, salvo en los casos expresamente tipificados por la ley, que son, por ello, excepcionales.

15 Sin embargo, existen ciertas voces, como Arjona Guajardo-Fajardo, J.L. (1998) Promesas unilaterales y donaciones, Marcial Pons, Madrid-Barcelona, p. 127, que consideran posible incluir las declaraciones unilaterales dentro de las fuentes de las obligaciones.

16 Así, entre otras muchas, la STS de 6 de junio de 1916; STS de 25 de abril de 1924 y STS de 19 de mayo de 1932

17 Ahora bien, la promesa pública de recompensa, prevista en el art. 657 del BGB (se denomina auslobung), ha servido de excusa a cierto sector de la doctrina para admitirla como una declaración unilateral de voluntad. En virtud de la misma, un determinado individuo se obligaría a efectuar cierta prestación a favor de aquel que bien ejecute una actividad bien logre un concreto resultado. Tal promesa estaría dirigida a un número indeterminado de personas que serían, en definitiva, los potenciales ejecutores de la conducta o resultado que se persigue.

18 En este último sentido, sin ánimo agotador, la STS de 3 de febrero de 1973 -RJ 1973/403-; STS de 30 de septiembre de 1975 -RJ 1975/3408- y STS de 10 de junio de 1977 (RJ 1977/122).

19 Según Díez-Picazo, L. (1974) "Las declaraciones unilaterales de voluntad como fuente de obligaciones y la jurisprudencia del Tribunal Supremo (en torno a la sentencia de 3 de febrero de 1973)", Anuario de Derecho Civil, núm. 27, el único supuesto claro de declaración unilateral creadora de obligaciones es el de la promesa unilateral realizada credendi causa, es decir para compensar una actividad o un resultado que se espera o confía obtener. Se trata de la promesa de recompensa. No cabe, para este autor, ni la causa solvendi ni la causa donandi. La primera, porque presupone necesariamente la preexistencia de la obligación que se cumple; la segunda por los estrictos condicionamientos a que nuestro ordenamiento jurídico somete la validez y eficacia de las donaciones, en especial en cuanto a la forma. 
que el empresario en cuestión hubiera pactado con una determinada entidad su vigencia, quedando su observancia a cargo de un tercero.

\section{CONCLUSIONES}

La Responsabilidad Social Corporativa es un desafío tanto para las organizaciones actuales como las futuras a nivel global. Cada vez un número más significativo de empresas, con buen criterio, optan por asumir prácticas socialmente responsables en múltiples sectores de la actividad económica, lo que, a priori, debe ser valorado de manera favorable. Son, en este sentido, conscientes de que, en la economía actual de mercado, la legitimidad para poder operar viene auspiciada por todos aquellos grupos de interés con los que la organización se relaciona -stakeholders-. Nos encontramos ante un concepto que puede ser abordado desde distintos puntos de vista. En todo caso, todos ellos ofrecen argumentaciones coherentes para justificar, desde una perspectiva económica, social y moral, la necesidad de incorporar aspectos de responsabilidad social corporativa en la gestión empresarial.

Por lo que respecta al presente artículo de investigación, debemos precisar que nos hemos centrado en el valor jurídico que tales prácticas merecen cuando encuentran su origen en la sociedad que, de igual forma, los pone en práctica. $Y$ es que, como hemos tomado conciencia, en algunos supuestos, los documentos de referencia -frecuentemente serán códigos de conducta-, presentarán carácter unilateral, siendo redactados y verificados por la propia empresa que los implanta, sin existir aceptación por parte de sus destinatarios. Dicho de otro modo, como hemos analizado, no existe organismo, imparcial e independiente, encargado de controlar el cumplimiento de tal documento. En tales casos, podrían ser reputados como meras declaraciones unilaterales de voluntad, concebidas, en ciertos supuestos, como una estrategia comercial de imagen. 


\section{REFERENCIAS}

Guajardo, A. y Fajardo, J.L. (1998) Promesas unilaterales y donaciones, Marcial Pons, MadridBarcelona.

Arnaud, A.J. (2003) Critique de la raison juridique. Gouvernants sans frontirres - Entre mondialisation et post-mondialisation, Vol. 2, LGDJ, París.

Candela Quintanilla, R.M. (2012) "II Encuentro Nacional de Agentes Oficiales Prescriptores de Confianza Online", Autocontrol, núm. 172.

Cayón de las Cuevas, J. (2011) "Regulación y autorregulación en el comercio electrónico: especial consideración de los códigos de conducta como instrumento de soft law". En Tomilla Urbina, J. (Dir.) y Álvarez Rubio, J. (Coord.), La protección jurídica de los consumidores como motor de desarrollo económico, Thomson Reuters y Civitas, Navarra.

De La Cuesta Rute, J.M. (2008) "La autorregulación como regulación jurídica". En Real Pérez, A. (Coord.), Códigos de conducta y actividad económica: una perspectiva jurídica, Marcial Pons, Madrid-Barcelona.

Díez Picazo, L. (1974) "Las declaraciones unilaterales de voluntad como fuente de obligaciones y la jurisprudencia del Tribunal Supremo (en torno a la sentencia de 3 de febrero de 1973)", Anuario de Derecho Civil, núm. 27.

Díez Picazo, L. (1996) Fundamentos del Derecho Civil Patrimonial. Las relaciones obligatorias, Tomo II, Madrid: Civitas.

Duprat, J.P. (2010) "Los códigos de conducta vistos por un jurista francés". En Real Pérez, A. (Coord.), Códigos de conducta y actividad económica: una perspectiva jurídica, Marcial Pons, Madrid-Barcelona.

Illescas Ortiz, R. (2003) "La autorregulación, entre la quiebra de la relatividad y la obligatoriedad de la declaración unilateral de voluntad", Derecho Privado y Constitución, núm. 17.

López Jiménez, D. y Martínez López, F.J. (2010) "Nuevas tendencias en materia de responsabilidad social corporativa: los códigos de conducta reguladores del comercio electrónico", Revista de Responsabilidad Social de la Empresa, núm. 1.

Maluquer De Motes Bernet, C. (2011) "Códigos de conducta y buenas prácticas en la gestión da datos personales". En LLACER MATACÁS, M.R. (Coord.), Protección de datos personales en la sociedad de la información u la vigilancia, La Ley, Madrid.

Martí Miravalls, J. (2008) "Los códigos de conducta en las redes de franquicia: el modelo Americano versos el europeo", Revista de Derecho Mercantil, núm. 269.

Rodríguez De las Heras Ballel, T. (2009) "Espacio digital y autorregulación". En Real Pérez, A. (Coord.), Códigos de conducta y actividad económica: una perspectiva jurídica, Marcial Pons, Madrid-Barcelona.

Tato Plaza, A. (2010) "Líneas generales de la reforma del Derecho español contra la competencia desleal (parte II)", Autocontrol, núm. 150. 